This is the accepted version of the following article: Chau, D., Dennis, A. R., Lin, H., Zeitler, J. A., Tunnacliffe, A., 'Determination of Water Content in Dehydrated Mammalian Cells Using Terahertz Pulsed Imaging: A Feasibility Study', Current Pharmaceutical Biotechnology 17(2): 200-207, February 2016. The published manuscript is available at http://www.eurekaselect.com/136239/article 


\title{
Determination of Water Content in Dehydrated Mammalian Cells Using Terahertz Pulsed Imaging: A Feasibility Study
}

\author{
David Y.S. Chau ${ }^{1,2, *}$, Anthony R Dennis ${ }^{3}$, Hungyen Lin $^{4}$, J. Axel Zeitler ${ }^{4}$ and Alan Tunnacliffe ${ }^{1}$
}

${ }^{1}$ Cell and Organism Engineering Laboratory, Department of Chemical Engineering \& Biotechnology, New Museums Site, Pembroke Street, University of Cambridge, Cambridge, CB2 3RA, UK; ${ }^{2}$ Department of Pharmacy, School of Life \& Medical Sciences, University of Hertfordshire, College Lane, Hatfield, AL10 9AB, UK; ${ }^{3}$ Bulk Superconductivity Group, Department of Engineering, Trumpington Street, University of Cambridge, Cambridge, CB2 1PZ, UK; ${ }^{4}$ Terahertz Applications Group, Magnetic Resonance Research Centre, JJ Thompson Avenue, University of Cambridge, Cambridge, CB3 OHE, UK

\begin{abstract}
Mammalian cells are involved in a range of biotechnological applications and more recently have been increasingly exploited in regenerative medicine. Critical to successful applications involving mammalian cells are their long-term storage and transport, for which cryopreservation in liquid nitrogen is the most frequently used strategy. However, cryopreservation suffers from high costs, difficulties in transport logistics and the use of undesirable additives (e.g. animal sera or DMSO). An alternative approach, proposed as low cost, low maintenance and process-compatible, is viable desiccation of mammalian cells. Several groups claim to have achieved this, but the extent of desiccation in the cell samples concerned is not always clear, in part because of difficulties in determining very low water content. Although several techniques exist that are frequently used to quantify the amount of water in samples (e.g. FTIR spectroscopy, thermogravimetric analysis (TGA), NMR spectroscopy), the complexity of sample preparation, as well as the costs and time constraints involved are disadvantageous. Here, we assess a novel, rapid and low cost technique, i.e. terahertz (THz) spectroscopy, for the quantification of water content within dehydrated mammalian cell samples.
\end{abstract}

Keywords: Dehydration, desiccation, terahertz pulsed imaging, humidity, anhydrobiotic engineering.

\section{INTRODUCTION}

Current technologies in regenerative medicine and biotechnology exploit individual biological reagents, such as growth factors, matrix components and enzymes, but increasingly also involve whole cells (e.g. therapeutic stem cells, tissue engineering, cell banking, in vitro meat generation) [1]. For cells, a crucial aspect of their successful application in novel technologies is the ability to achieve longterm storage without affecting stability, functionality and viability [2]. Unfortunately, current storage techniques such as cryopreservation are not without their problems, which include limited shelf life and reduced product functionality [3], high capital and running costs [4], the use of toxic reagents [5], risk of (cross-)contamination [6] and, in some cases, genetic or phenotypic drift from the original sample [7].

Cryopreservation (i.e. storage in liquid nitrogen) is the most established approach to long-term mammalian cell line banking but, in addition to the drawbacks highlighted above, it is subject to an additional constraint concerned with the elimination of animal-derived products (i.e. serum) to satisfy

*Address correspondence to this author at the Department of Pharmacy, School of Life \& Medical Sciences, University of Hertfordshire, College Lane, Hatfield, AL10 9AB, UK; Tel: +44 (0)1707 285060; Fax: +44 (0)1707 284115; E-mail: d.chau@herts.ac.uk regulatory legislation and ethics [8-11]. Moreover, there is also a requirement for the removal or replacement of particular cryoprotective agents (CPAs) (e.g. DMSO, ethanol, PEG), which can be toxic, induce cell differentiation, and cause other problems further downstream due to insufficient removal during processing [12]. Therefore, despite significant research on the development of novel CPAs, additives and supplements [13-15], and their delivery to the cell [1618], alternative techniques are being sought for the long-term storage of mammalian cells.

Although water is essential to life, certain animals (e.g. nematodes, tardigrades and bdelloid rotifers), yeasts (e.g. Saccharomyces spp., Pichia spp.) and plants (Craterostigma plantagineum, Tortula ruralis) can survive almost complete desiccation, with residual water contents below $\sim 10 \% \mathrm{w} / \mathrm{w}$. These organisms are stably ametabolic over long time periods in the dry state and resume normal life processes upon rehydration [19-21]. This phenomenon is known as desiccation tolerance or anhydrobiosis ('life without water') and raises the possibility of translating the underlying mechanism(s) to mammalian cells as a technology with particular applications in long-term storage. Several reports in the literature claim successful anhydrobiotic engineering of mammalian cells, whereby cells are preserved in a manner analogous to anhydrobiosis, i.e. dried, without freezing, in a viable state [22-26]. However, in the majority of these cases, it can 
be argued that the water content may not have been accurately assessed [27]. Although FT-IR spectroscopy, thermogravimetric analysis (TGA) and/or NMR spectroscopy are often used to assess the water content of samples, they have limited value in biological applications due to a variety of reasons that include difficulties in sample preparation, scaleup, operating costs, processing time and sensitivity $[26,28$, 29]. As an alternative, we propose the use of terahertz $(\mathrm{THz})$ spectroscopy as a potential, low cost, high-throughput and sensitive technique for the characterisation and quantification of water content in dehydrated mammalian cells. In particular, this investigation focuses on drying cells using an evaporative water loss approach and discusses the data in the context of the development of a desiccation-tolerant mammalian cell line.

\section{MATERIALS AND METHODS}

Chemicals were purchased from Sigma-Aldrich (Poole, UK) unless otherwise stated. Sterile preparation of stock solutions and chemicals was performed either by filtration through a $0.22 \mu \mathrm{m}$ Whatman sterile filter or by autoclaving at $121^{\circ} \mathrm{C}$ at 1.1 bar for $30 \mathrm{~min}$.

\section{Cell Culture}

The adherent mouse embryonic fibroblast cell line Flp-

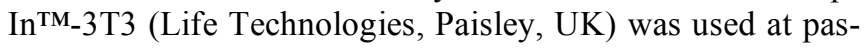
sage numbers $<15$ throughout this investigation. Cells were grown and maintained, in vitro, as monolayers in T-flasks using DMEM, supplemented with $10 \% \mathrm{v} / \mathrm{v}$ FCS, $4 \mathrm{mM}$ L-glutamine, $1 \% \mathrm{v} / \mathrm{v}$ penicillin-streptomycin solution and $100 \mu \mathrm{g} / \mathrm{ml} \mathrm{Zeocin}{ }^{\mathrm{TM}}$. Flasks were kept in a humidifiedatmosphere incubator at $37^{\circ} \mathrm{C}$ and with $5 \% \mathrm{v} / \mathrm{v} \mathrm{CO}_{2}$. Cells were never allowed to reach greater than $95 \%$ confluency before passaging. For detachment, a standard trypsinisation protocol was performed using $0.25 \% \mathrm{w} / \mathrm{v}$ trypsin $/ 2 \mathrm{mM}$ EDTA solution in PBS.

\section{Cell Viability and Proliferation}

Cell number and viability estimations were performed using the standard trypan blue exclusion technique, as previously described [30,31], by means of a $0.22 \mu \mathrm{m}$ sterilefiltered $0.4 \% \mathrm{w} / \mathrm{v}$ trypan blue solution and a haemocytometer. Non-viable cells stained blue due to loss of membrane integrity; viable cells remained colourless. Additionally, proliferation and metabolic activity of the cells were assessed using the CellTiter AQ One Solution/MTS Cell Proliferation $^{\mathrm{TM}}$ assay kit (Promega, Southampton, UK). Assays were performed, with reduced lighting, by the addition of a 1:5 ratio of MTS reagent to the culture medium (i.e. $20 \mu \mathrm{l}$ of MTS per $100 \mu l$ culture medium in a 96-well plate; $100 \mu \mathrm{l}$ of MTS per $500 \mu 1$ culture medium in a 24 -well plate). Samples were then incubated in a humidified-atmosphere incubator at $37^{\circ} \mathrm{C}$ and $5 \% \mathrm{v} / \mathrm{v} \mathrm{CO}$ for 90 min before $100 \mu 1$ of each sample well was transferred to a new 96-well plate and the absorbance read at $490 \mathrm{~nm}$ using a Perkin Elmer EnVision 2104 Multi-label plate reader. Relative Metabolic Activity (\%) is defined as the metabolic activity of the (dehydrated) sample divided by the metabolic activity of the appropriate control and represented as a percentage value.

\section{Attachment and Spreading Assay}

Cells were seeded on the relevant substrate and allowed to attach and spread for the corresponding timepoint. Samples were then fixed in $3.7 \% \mathrm{w} / \mathrm{v}$ paraformaldehyde, permeabilised by the addition of $0.1 \% \mathrm{v} / \mathrm{v}$ Triton X-100 in PBS, before being stained with May-Grunwald $(0.25 \% \mathrm{w} / \mathrm{v}$ in methanol) and Giemsa (0.4\% w/v in methanol, diluted 1:50 with water) stains. Cells were then viewed at $\times 10$ magnification using a Leica DMIRB microscope. Three separate fixedsize random fields per sample were photographed with the integrated Nikon E4500 CoolPix digital camera. Cells were distinguished and characterised based on the presence of a clear halo of cytoplasm surrounding their nucleus, as previously described [30-32].

\section{Cell Sample Preparation}

For the majority of assays in this investigation, Flp-In ${ }^{\mathrm{TM}}$ 3T3 cells were seeded on a polyester substrate for ease of handling, sampling and analysis. Individual discs $(12.7 \mathrm{~mm}$ diameter, $175 \mu \mathrm{m}$ thick) of Melinex polyester (polyethylene terephthalate) film were created using a commercially available disc punch (both from Agar Scientific, Essex, UK) and used as the scaffold for cell attachment [33]. Prior to use, discs were soaked in $70 \% \mathrm{v} / \mathrm{v}$ ethanol overnight, then washed in sterile distilled water and air dried in a laminar flow hood ( $\sim 30 \mathrm{~min})$. Dry individual discs were placed into the wells of a 24 -well plate before $0.5 \mathrm{ml}$ of $0.01 \% \mathrm{w} / \mathrm{v}$ polyL-lysine solution $\left(\mathrm{M}_{\mathrm{w}}: 70 \mathrm{~K}-150 \mathrm{~K}\right)$ was added to each well. The plate was then placed in a humidified-atmosphere incubator at $37^{\circ} \mathrm{C}, 5 \% \mathrm{v} / \mathrm{v} \mathrm{CO}_{2}$, and left overnight. The plate was manually agitated at least twice during this procedure to ensure that all surfaces were coated in poly-L-lysine solution. Discs were then removed from the wells, rinsed with sterile PBS, placed into the wells of a new 24-well plate and allowed to dry in the laminar flow hood $(\sim 30 \mathrm{~min})$. Cells, in complete DMEM, were then added directly to the treated discs $\left(0.5 \mathrm{ml}\right.$ of a $3 \times 10^{5}$ cells $/ \mathrm{ml}$ suspension) before being returned to a humidified-atmosphere incubator $\left(37^{\circ} \mathrm{C}, 5 \%\right.$ $\mathrm{v} / \mathrm{v} \mathrm{CO}_{2}$ ) and left overnight. The presence of cells on the discs was confirmed using light microscopy and samples with $>85 \%$ confluency (uniform and as a monolayer) were used for experiments thereafter.

\section{Cell Drying}

Controlled drying was achieved using two different techniques referred to as "air drying" and "humidity drying". In each case, the samples consisted of $\sim 1.5 \times 10^{5}$ cells attached to a Melinex disc.

\section{Air Drying of Cell-Melinex Discs}

Plates containing the cell-Melinex discs were removed from the incubator and the cell distribution confirmed as described. Thereafter, cell culture medium was removed from wells using a vacuum aspirator. Following complete removal of any residual liquid (by tilting the sample disc and then blotting with tissue), the plates were positioned in the centre of an empty, unlit Microflow 2 Advanced Biosafety Class II laminar flow cabinet (Bioquell UK Ltd., Andover, UK). This ensured that the air flow was uniform throughout the drying process $(54 \%$ relative humidity $(\mathrm{RH}) \pm 2 \%$; 
$21.1^{\circ} \mathrm{C} \pm 0.1^{\circ} \mathrm{C} ; \mathrm{n}=3$; equilibrated after $1 \mathrm{~h}$ ) and also minimized any additional evaporation or heating due to a direct light source. Cells were dried for the times described in Results before addition of $0.5 \mathrm{ml}$ complete media and relocated to a humidified-atmosphere incubator $\left(37^{\circ} \mathrm{C}, 5 \% \mathrm{v} / \mathrm{v} \mathrm{CO}_{2}\right)$ for $1 \mathrm{~h}$ prior to assessment. In contrast, where water content was to be determined, samples were immediately assessed without rehydration or were taken to the appropriate apparatus in an air-tight box.

\section{Humidity Drying of Cell-Melinex Discs}

Following removal of the cell culture media as described above, samples were transferred to custom-converted $6 \mathrm{~L}$ clip-lock Tupperware air-tight polypropylene boxes $(30 \mathrm{~cm} \mathrm{x}$ $20 \mathrm{~cm} \times 10 \mathrm{~cm}, \mathrm{~W} \times \mathrm{D} \times \mathrm{H}$ ) containing $\mathrm{CuSO}_{4}$ and $\mathrm{BaCl}_{2}$, which acted as humidity chambers with $98 \% \mathrm{RH}$ and $90 \%$ $\mathrm{RH}$, respectively, as previously described [34]. The humidity chambers contained saturated solutions with excess salt protruding above the water level; samples were positioned above the interface using plastic inserts. Two chambers per humidity condition were prepared and samples distributed between them. When required for analysis, samples were removed from alternate chambers to ensure consistent humidity and temperature, or were equilibrated beforehand. A humidity level of $95 \% \mathrm{RH}$ was achieved by placing samples directly into a Sanyo MCO-18AIC humidified incubator (Panasonic Biomedical, Loughborough, UK). The humidity tray of the incubator was maintained as suggested by the manufacturer using sterile distilled water. The \% RH was independently confirmed using an external AllA hygrothermometer (Thermometers Direct Ltd., Aldershot, UK) following stabilization within each environment for $24 \mathrm{~h}$. In all cases, samples and humidity chambers were incubated in a humidified-atmosphere incubator $\left(37^{\circ} \mathrm{C}, 5 \% \mathrm{v} / \mathrm{v} \mathrm{CO}_{2}\right)$ for the relevant timepoints before viability of the cells or the water content of the discs was determined.

\section{Water Content of Cell-Melinex Discs}

The water content of the dehydrated samples $\left(\sim 1.5 \times 10^{5}\right.$ cells per Melinex disc) was assessed using TGA and $\mathrm{THz}$ spectroscopy. For all samples, the presence and uniform distribution of cells was confirmed using optical microscopy prior to analysis.

\section{Thermogravimetric Analysis (TGA)}

The absolute mass change of the samples was determined using TGA and assumed to correspond to water in the cellMelinex discs. Briefly, on removal of culture medium, the underside of each disc was wiped or blotted with tissue to remove any excess moisture. To reduce variability, four discs were used (per measurement) and stacked on top of one another before being transferred to the crucible stage of a Setaram LABSYS Evo TGA-DTA $\backslash$ DSC machine (Setaram, Cambridge, UK). Samples were subjected to a ramped temperature profile: $20^{\circ} \mathrm{C}-90^{\circ} \mathrm{C}$ (at $1^{\circ} \mathrm{C} / \mathrm{min}$ ), an isotherm at $90^{\circ} \mathrm{C}$ for $4 \mathrm{~h}$, and then $90^{\circ} \mathrm{C}-20^{\circ} \mathrm{C}\left(\right.$ at $1^{\circ} \mathrm{C} / \mathrm{min}$ ). To ensure a stable base line and to reduce noise, the differential scanning calorimetry (DSC) probe was disconnected and removed from the sample chamber, the $\mathrm{Tg}$ rod was used in small measurement range, no gas flow was permitted during acqui- sition (although a purge of the empty chamber with dry argon was performed before each analysis) and the machine was operated remotely (after loading). The initial and final sample weights were measured and used to calculate moisture content. Absolute dry weight was determined by incubating representative samples in a vacuum oven for $48 \mathrm{~h}$ at $90^{\circ} \mathrm{C}$ before TGA.

\section{Terahertz Pulsed Imaging}

Terahertz pulsed imaging (TPI) reflection measurements of the samples were acquired using a TPI Imaga 2000 (TeraView Ltd., Cambridge UK) system with a spectral range of $60 \mathrm{GHz}$ to $3 \mathrm{THz}$. Depending on the sample material, THz pulses incident on a surface of a sample can penetrate through different thickness layers, whereby at each interface or abrupt change in refractive index or optical density of the material would give rise to a reflection of a portion of the terahertz pulse to the detector. In short, $\mathrm{THz}$ radiation is generated by pumping a biased photoconductive antenna with an ultrashort laser pulse from an ultrafast laser. The emitted $\mathrm{THz}$ pulse is collected, collimated, and then focused onto a sample under test to a diffraction-limited spot by a pair of high resistivity silicon lenses To facilitate the handling of the sample, the samples were attached to black, carbon-based, adhesive discs (Agar Scientific, Essex, UK) before being held in place, under suction, on the six-axis robotic arm provided with TPI Imaga 2000. Surface height maps of the discs were initially acquired using a laser gauge with a wavelength of $670 \mathrm{~nm}$ to precisely model the surface shape of the sample under investigation. This is then followed by whole waveform acquisition of the reflected terahertz pulse across the surface of the disc (point-to-point mapping mode with $200 \mu \mathrm{m}$ or $500 \mu \mathrm{m}$ step size, total time $\sim 15$ min or $<1 \mathrm{~min}$, respectively). Thereafter, the spatial distribution of the Surface Refractive Index (SRI) maps were extrapolated and calculated from the peak intensity of the acquired reflected terahertz waveform(s) using the TPIview software (TeraView Ltd., Cambridge, UK). The SRI corresponds to the effective refractive index of the sample disc at the surface of the disc over a depth of approximately $0<\mathrm{d}<$ $30 \mu \mathrm{m}$ relative to the sample surface. In addition, total water content per (surface area) sample was calculated by extrapolating from the raw data set and is related to the actual number of pixels acquired during the scan. Further details have been summarized previously [35-37].

\section{Statistical Analysis}

Microsoft Excel 2011 (v14.3.4) and GraphPad (InStat, v3.01) software were used to calculate mean values and standard deviations for each sample, and the differences between the means were assessed using Student's $t$-test (twotailed) or one-way ANOVA with post-hoc Tukey test as appropriate, with $p<0.05$ considered significant.

\section{RESULTS}

\section{Cell Viability after Drying}

Flp-InTM-3T3 cells, grown on Melinex discs for ease of handling and analysis, were subjected to a variety of drying protocols and after rehydration were assessed for viability using the MTS assay, which measures cellular metabolic 
activity. The viability of revived cells decreased with the duration of desiccation using either an air drying or a humidity drying (i.e. 98\% RH, 95\% $\mathrm{RH}$ and 90\% $\mathrm{RH}$ ) protocol (Fig. 1). In all four cases, ANOVA analyses demonstrated a significant reduction in cell viability $(p<0.01)$ as early as $3 \mathrm{~h}$ after the onset of desiccation, giving " $50 \%$ Lethal Dose" (i.e. $\mathrm{LD}_{50}$ ) values of $<6 \mathrm{~h}$ ( $<3 \mathrm{~h}$ for the air dried sample). These data being comparable to previous results $[25,34,38]$.

\section{Water Content Determination}

If water loss is responsible for the cell death observed in the above experiments, viability should correlate with moisture content in cells. Conversely, in cells subjected to successful anhydrobiotic engineering, we anticipate that viability should remain high despite low moisture content. It is therefore crucial for the development of anhydrobiotic engineering that residual moisture can be measured accurately, but this is technically challenging because the volumes of water in cell samples are very small. Techniques such as Karl-Fischer titration, for example, are unlikely to be sufficiently sensitive. In addition, where there are concerns about whether all cells within a dehydrated population are equally dry, it would be valuable to know the distribution of water remaining in the sample. With this in mind, we have examined two different approaches to moisture determination in dehydrated cells.

The moisture contents of the cell-Melinex samples were assessed using TGA due to its prevalence within the literature for (scaled-up) biological samples. Initial calibration experiments (Fig. 2) indicated that samples containing as little as $2.5 \mu \mathrm{l}$ water were clearly resolved using the assigned temperature profile $\left[19^{\circ} \mathrm{C}-90^{\circ} \mathrm{C}\right.$ (at $\left.1^{\circ} \mathrm{C} / \mathrm{min}\right), 90^{\circ} \mathrm{C}$ for $4 \mathrm{~h}$, $90^{\circ} \mathrm{C}-19^{\circ} \mathrm{C}$ (at $\left.\left.1^{\circ} \mathrm{C} / \mathrm{min}\right)\right]$. In fact, the isothermic step itself $\left(90^{\circ} \mathrm{C}, 4 \mathrm{~h}\right)$ was sufficient to evaporate $100 \mu \mathrm{l}$ of water; samples of $50 \mu \mathrm{l}$ were also completely dried after $\sim 145 \mathrm{~min}$ (data not shown). The control sample (i.e. Melinex discs with no cells attached) did not contribute a mass change.

The mass water content for samples subjected to air drying and humidity drying following the aforementioned temperature profile as documented in Table 1. Sample moisture content generally decreased with drying time for all the investigated conditions and, ultimately, reached the same final value $(1 \mathrm{mg}$ ) after $36 \mathrm{~h}$ of dehydration (with the exception of the air-dried sample). In short, the water content of the cells follows the observed survival data of (Fig. 1).

While TGA allows the determination of moisture content in cells, it gives no information on its distribution. In contrast, terahertz pulsed imaging can indicate both the content and distribution of water in a sample. When a terahertz pulse is directed onto a sample, a train of pulses will be reflected back from the sample surface and subsequent interfaces. The amplitude and timing of these pulses can be measured precisely and can be used to calculate the quantity of water present. Furthermore, with the TPI instrument used, a scan can be performed over several millimeters in both $x$ and $y$ directions. This allows a spatial image of absorption intensity, and thus water content, to be generated with high accuracy.

To demonstrate this for mammalian cells attached to a Melinex disc, a specific configuration (i.e. a cross) was created by scraping through a monolayer of hydrated cells with a plastic inoculation loop (Fig. 3A , B). The reflected terahertz electric field of the sample was then measured at 200 $\mu \mathrm{m}$ stepsize for an area of cells including the cell-free cross.

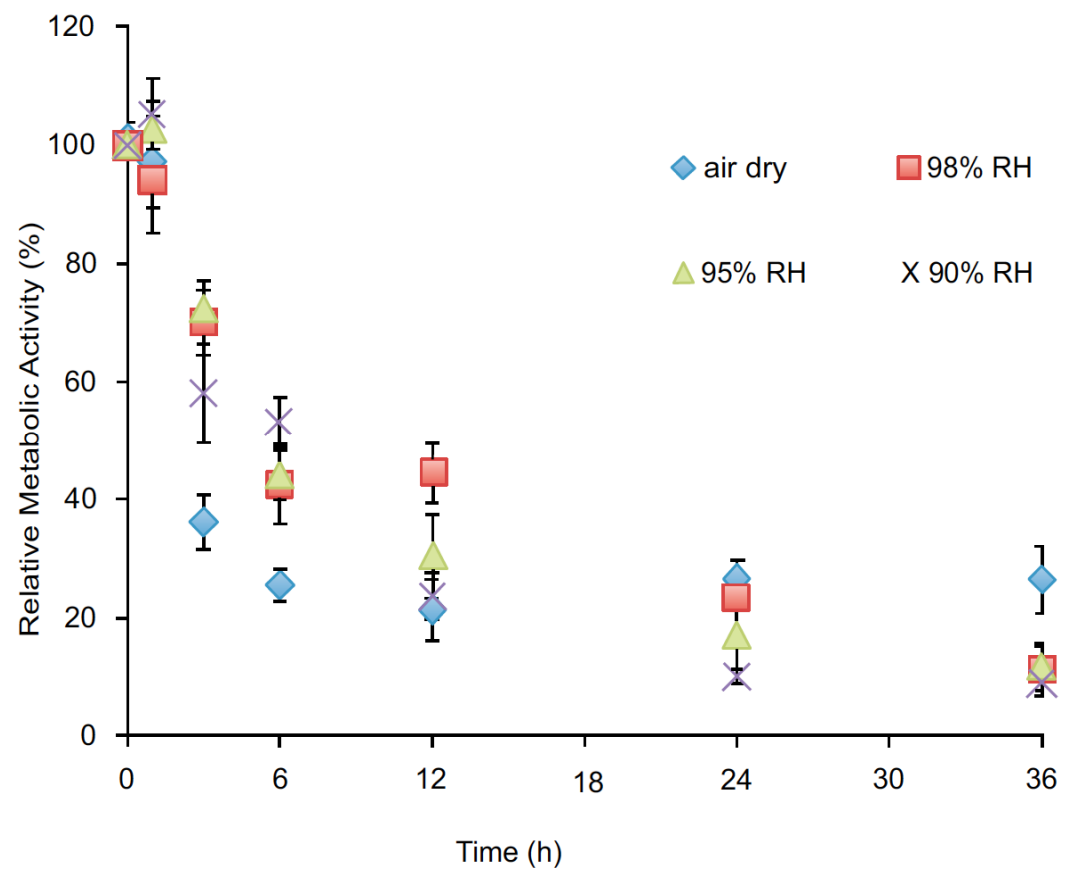

Fig. (1). The relative metabolic activity of Flp-In ${ }^{\mathrm{TM}}-3 \mathrm{~T} 3$ cells following revival in complete DMEM, post-dehydration. Samples were assessed using the MTS assay according to the manufacturer's instructions: a 1:5 ratio of MTS reagent was added to culture medium, incubated in a humidified-atmosphere incubator at $37^{\circ} \mathrm{C}$ and with $5 \% \mathrm{CO}_{2}$ for $90 \mathrm{~min}$ before the absorbance was read at $490 \mathrm{~nm}$ using a Perkin Elmer EnVision 2104 Multi-label plate reader. Values represent the mean value of $n=5 \pm$ standard deviation (SD). 


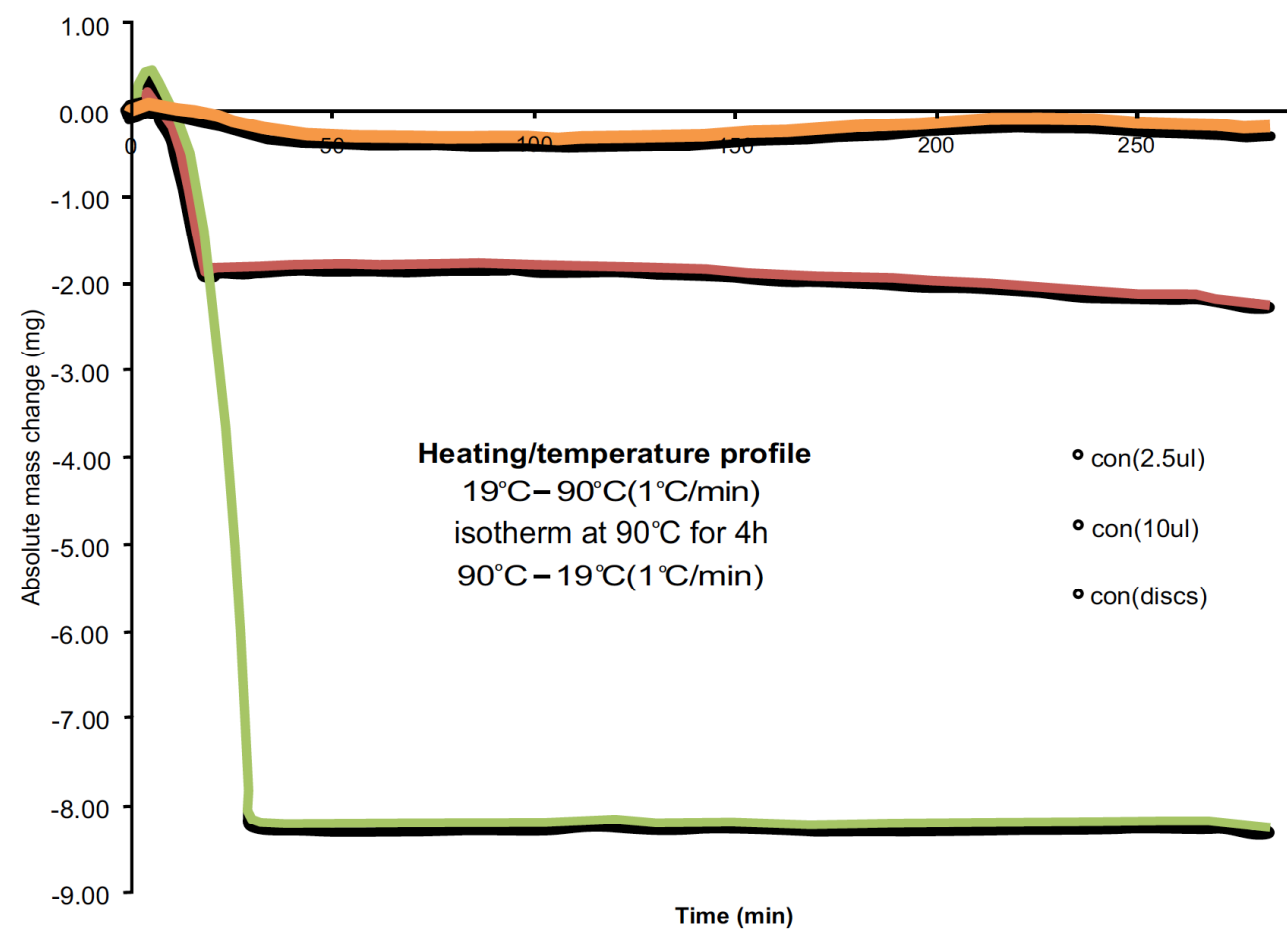

Fig. (2). TGA calibration and detection limit. Samples of DMEM (2.5 $\mu 1,10 \mu \mathrm{l})$ or control Melinex discs were loaded onto a Setaram LABSYS Evo TGA-DSC machine and subjected to a ramped heating profile $\left(20^{\circ} \mathrm{C}-90^{\circ} \mathrm{C}\left(\right.\right.$ at $\left.1{ }^{\circ} \mathrm{C} / \mathrm{min}\right)$, an isotherm at $90^{\circ} \mathrm{C}$ for $4 \mathrm{~h}$, and then $90^{\circ} \mathrm{C}-20^{\circ} \mathrm{C}\left(\right.$ at $\left.\left.1{ }^{\circ} \mathrm{C} / \mathrm{min}\right)\right)$ to ascertain the sensitivity of the machine.

Table 1. TGA analyses of the water mass content of dehydrated Flp-In ${ }^{\mathrm{TM}}-3 \mathrm{~T} 3$ cells.

\begin{tabular}{|c|c|c|}
\hline \multicolumn{3}{|c|}{ Mass water content (mg) } \\
\hline Time-point (h) & Sample & 180 mins \\
\hline 3 & Air dried & $8 \pm 1$ \\
\hline 3 & Incubator $(98 \% \mathrm{RH})$ & $12 \pm 1$ \\
\hline 3 & Incubator $(95 \% \mathrm{RH})$ & $11 \pm 1$ \\
\hline 3 & Incubator $(90 \% \mathrm{RH})$ & $7 \pm 1$ \\
\hline 12 & Air dried & $3 \pm 1$ \\
\hline 12 & Incubator $(98 \% \mathrm{RH})$ & $8 \pm 1$ \\
\hline 12 & Incubator $(95 \% \mathrm{RH})$ & $7 \pm 2$ \\
\hline 12 & Incubator $(90 \% \mathrm{RH})$ & $4 \pm 2$ \\
\hline 36 & Air dried & $2 \pm 1$ \\
\hline 36 & Incubator (98\% RH) & $1 \pm 1$ \\
\hline 36 & Incubator $(95 \% \mathrm{RH})$ & $1 \pm 0$ \\
\hline 36 & Incubator $(90 \% \mathrm{RH})$ & $1 \pm 1$ \\
\hline
\end{tabular}

Four cell-Melinex samples were dehydrated before being loaded onto a Setaram LABSYS Evo TGA-DSC machine and subjected to a ramped heating profile: $20^{\circ} \mathrm{C}-90^{\circ} \mathrm{C}$ (at $1^{\circ} \mathrm{C} / \mathrm{min}$ ), an isotherm at $90^{\circ} \mathrm{C}$ for $4 \mathrm{~h}$, and then $90^{\circ} \mathrm{C}-20^{\circ} \mathrm{C}$ (at $1{ }^{\circ} \mathrm{C} / \mathrm{min}$ ). Initial and final sample weights were measured and used to calculate moisture content. Absolute dry mass was determined by incubating representative samples in a vacuum oven for $48 \mathrm{~h}$ at $90^{\circ} \mathrm{C}$ before TGA. Values represent the mean value of $\mathrm{n}=3 \pm$ standard deviation (SD). Modal values were extrapolated from the raw data set.
In essence, the contrast mechanism of the reflection measurement can be calculated from the refractive indices:

$$
\text { E_sam }=\operatorname{Eref}(\mathrm{n} 2-1) /(\mathrm{n} 2+1)
$$

Where $\mathrm{n}_{2}$ is the index of water or plastic

The map of reflected $\mathrm{THz}$ electric field generated clearly shows the cross as a region of low water content (dark blue pixels, Melinex disc has a refractive index of 1.712 [39]), while the surrounding areas contain a higher level of water moisture (yellow and magenta pixels, the refractive index of water is 2.04 [40] due to the presence of cells (Fig. 3C). A graphical representation of the relative terahertz reflectivity, and therefore sample water content, is shown in (Fig. 3D), where the number of pixels with specific reflection magnitudes are plotted, and from which the mean reflectivity for the sample, in arbitrary units, can also be derived (i.e. $31 \pm 4 \%$ ). This is in close agreement with the expected reflectivity of 0.34 based on the refractive index of water. In addition, manipulation of the raw terahertz data can provide the summative reflectivity value across the whole disc. In short, both relative moisture content and distribution of water across the cell population can be determined using terahertz pulsed imaging.

Calibration of the TPI instrument was performed using a dried $\left(90^{\circ} \mathrm{C}, 48 \mathrm{~h}\right)$ and a fully hydrated cell-Melinex disc to give lower and upper mean peak intensity values of $25 \pm 2 \%$ and $58 \pm 7 \%$ (arbitrary units), respectively, as seen in (Fig. 4A). Again, the peak intensity value of $25 \%$ for the Melinex disc alone can be validated by the expected reflectivity of 0.26 determined using the refractive index of polyester. As can be seen, a high mean peak intensity value, i.e. higher reflection magnitudes of terahertz waves indicate a presence of water moisture. 
A

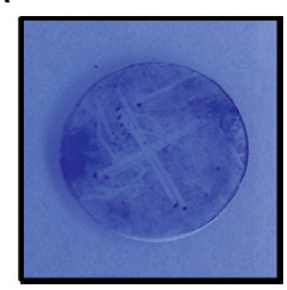

B

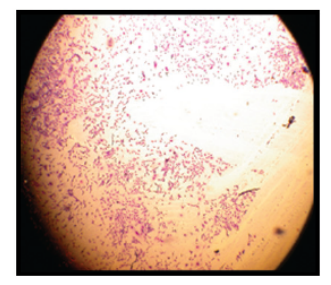

C

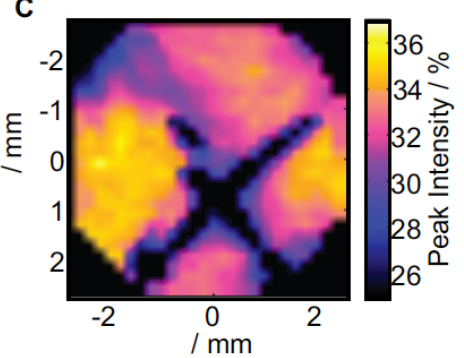

D

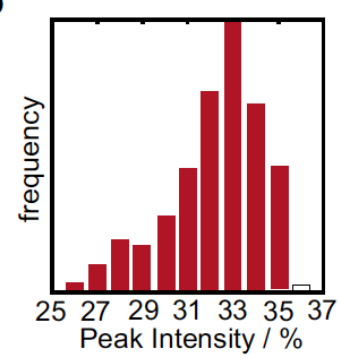

Fig. (3). THz calibration and optimisation of operating conditions. (A) image depicting the "cross" configuration created on a monolayer of hydrated cells and stained using May-Grunwald and Giemsa dual stain; (B) the marked sample as viewed under 10x magnification through a Leica DMIRB microscope; (C) THz reflectivity map of the sample at $200 \mu \mathrm{m}$ step-size acquisition; (D) corresponding "peak intensity" histogram profile of the marked cell-sample.

A
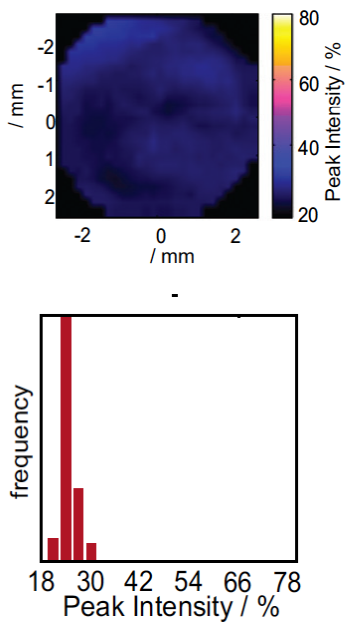

control (dry)
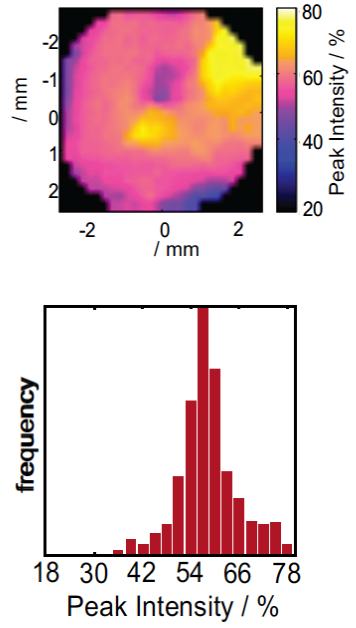

control (hydrated)
B
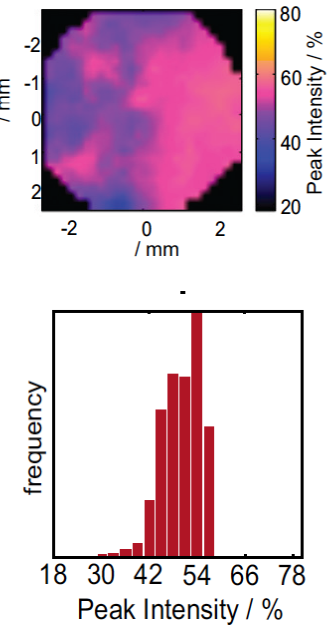

$98 \% \mathrm{RH}(3 \mathrm{~h})$
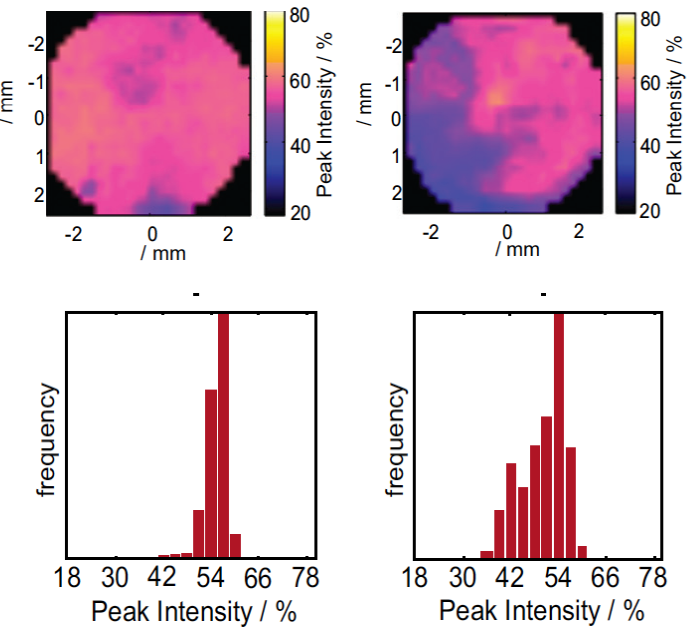

95\% RH (3h)

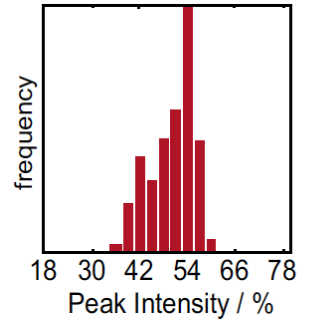

$90 \% \mathrm{RH}(3 \mathrm{~h})$

Fig. (4). THz calibration and analyses of dehydrated cell-Melinex discs. (A) Calibration of the TPI Imaga 2000 was achieved using dry and hydrated control samples, located $7 \mathrm{~mm}$ in front of the silicon optics and then scanned within the spectral range of $60 \mathrm{GHz}$ to $3 \mathrm{THz}$ at 200 $\mu \mathrm{m}$ step-size acquisition. (B) Representative THz reflectivity map and "mean count of pixels" histograms of humidity-dried cell-Melinex disc samples.

Having established working parameters for terahertz pulsed imaging of cell monolayers, samples dried at $98 \%$, 95\% and $90 \% \mathrm{RH}$ for $3 \mathrm{~h}$ were analysed (Fig. 4B). The quantities of water present in these samples were comparable, i.e. $50 \pm 5 \%(98 \% \mathrm{RH}), 55 \pm 3 \%(95 \% \mathrm{RH})$ and $50 \pm 5 \%$ $(90 \% \mathrm{RH})$, and lower than in a fully hydrated cell sample, indicating a degree of dehydration. However, samples analysed using TGA (i.e. mass water content; Table 1) demonstrated a clear trend of reducing water content, i.e. $12 \pm 1 \mathrm{mg}$ (98\% RH), $11 \pm 1 \mathrm{mg}(95 \% \mathrm{RH})$ and $7 \pm 1 \mathrm{mg}(90 \% \mathrm{RH})$, respectively. This may be due to variation in sample preparation between experiments, detection sensitivity or the inability of TPI to distinguish between intracellular and surface bound water. It is important to note in this context that we have investigated using terahertz reflection imaging to assess the water content rather than absorption spectroscopy in transmission. While the transmission measurements are likely to yield a much higher sensitivity due to the much higher absorption coefficient of water $\left(220 \mathrm{~cm}^{-1}\right.$ at $1 \mathrm{THz}$
[41] compared to the absorption from the Melinex disc (20 $\mathrm{cm}^{-1}$ at $1 \mathrm{THz}$ [39], we decided that the reflection measurement is the far more sensible geometry from an application point of view in cell biology. For accurate absorption measurements it would be essential to know the exact thickness of the dried film in addition to the terahertz transmission measurements, information that is not readily available during the drying process as the sample geometry keeps changing.

\section{DISCUSSION}

Drying in a controlled manner is the first step in the adaptation of mammalian cells for desiccation tolerance. In this investigation, cells were dehydrated at defined humidity levels (i.e. $98 \% \mathrm{RH}, 95 \% \mathrm{RH}$ and $90 \% \mathrm{RH}$ ) and within a laminar flow cabinet (i.e. air drying) for specific time periods prior to assessment. Under these conditions, cell survival was critically reduced after $3 \mathrm{~h}$ or more of dehydration. Cells subjected to air drying experienced the most dramatic decline in viability, most likely due to the rapid removal of 
water by the laminar flow mechanism. Strikingly, drying under three different controlled humidity conditions gave very similar survival profiles and, although viability initially fell more slowly than with air drying, cells in all drying regimes suffered approximately the same loss of metabolic activity after 24-36 h. This suggests that significant improvements in cell survival are unlikely to be achieved by reducing the initial rate of drying by modification of local humidity conditions.

The determination of the moisture content of dehydrating cell samples is crucial. Although several techniques exist that could be used for the determination of water content in a biological sample [42, 43], for this investigation we used TGA due to its simplicity. However, the sensitivity of TGA is subject to individual machine specifications: our protocol can detect sufficiently low levels of moisture within a sample of $\sim 2.5 \mu \mathrm{l}$ water. The TGA results confirm that residual moisture, for both air drying and humidity drying, is proportional to drying period. The end point for all drying conditions, following $36 \mathrm{~h}$ of dehydration, was a similar residual mass $(\sim 1 \mathrm{mg})$ which could be attributed to the presence of bound/intracellular moisture within the sample. As anticipated, water content values paralleled the viability of the mammalian cells; in essence, higher residual moisture content of the samples resulted in higher cell viability.

Following the appropriate optimisation and calibration of the TPI instrument, successful THz analysis was achieved and was capable of distinguishing between dry and hydrated samples with sufficient range to assess samples with intermediate water content. The lack of a strict correlation between residual water values obtained from TGA and TPI needs further analysis, but may reflect sample variation or the limited differences in refractive index of wet to dry cells. As well as moisture content, it was possible to derive a specific profile from the TPI analysis that represented the distribution of moisture in a monolayer of cells. Terahertz radiation is strongly absorbed by water, can penetrate up to 100 $\mu \mathrm{m}$ into the sample and can provide sub-millimeter spatial resolution $[44,45]$. Accordingly, reflectivity maps were generated for all the samples including the dehydrated control, which could be partly explained by incomplete drying, sensitivity of the TPI or noise from samples following transport. Despite this, the $\mathrm{THz}$ analyses raise two interesting observations: (i) the apparent concentration of water towards the bottom of the Melinex disc, and (ii) distribution of water/cells on the surface of a sample. This additional information would prove advantageous in translational applications or further analyses, i.e. cell revival from a dehydrated state or FT-IR spectroscopy, which rely on the selection of a representative sample from a larger population.

Interest in the biomedical field has led to the examination of dry preservation as a feasible technique for long-term mammalian cell banking. The storage of cells in a desiccated state would not only prevent loss/damage/phenotype drift to a (commercial/therapeutic) cell line but also, significantly reduce storage costs (i.e. liquid nitrogen and associated infrastructure) and ease any transport logistics. Although several groups have reported success with cell drying techniques, the residual moisture content within cell samples is subject to clarification. Herein, we suggest that a combina- tion of techniques (e.g. TGA and $\mathrm{THz}$ spectroscopy) should be exploited to define the water content of the desiccated sample, with each technique providing a different perspective. The technology for the development of a desiccationtolerant mammalian cell is still in its infancy and is subject to a great deal of skepticism. However, we believe that by establishing defined and accurate methods for assessment and analysis, the possibility of a long-term bio-banking technique based on viable desiccation is achievable in the near future.

\section{CONFLICT OF INTEREST}

The author(s) confirm that this article content has no conflict of interest.

\section{ACKNOWLEDGMENTS}

This work was supported by European Research Council Advanced Investigator grant 233232 (AT) and an Isaac Newton Trust/University of Cambridge Early Career Support Grant (HL and JAZ). The authors would also like to thank Professor David Cardwell (Department of Engineering, University of Cambridge) for use of the TGA.

\section{AUTHORS' CONTRIBUTION}

DYSC: design of study, conducted all in vitro experiments, sample preparation, data analyses, writing of manuscript; ARD: conducted TGA experiments and data analysis, contributed to the draft of manuscript; HL: conducted THz experiments and data analysis; JAZ: conducted $\mathrm{THz}$ experiments and data analysis, contributed to the draft of manuscript; AT: design of study, data analyses, financial support, writing of manuscript.

\section{REFERENCES}

[1] Thieman, W.J.; Palladino, M.A. Introduction to Biotechnology, $3^{\text {rd }}$ Edition. Benjamin Cummings Publishers, US, PIE, 2012. ISBN 10: 0321766113

[2] Acker, J.P. Biopreservation of cells and engineered tissues. Adv Biochem. Eng. Biotechnol., 2007, 103, 157-187.

[3] Wang, W. Lyophilization and development of solid protein pharmaceuticals. Int. J. Pharm., 2000, 203(1-2), 1-60.

[4] Vaught, J.; Rogers, J.; Carolin, T.; Compton, C. Biobankonomics: Developing a sustainable business model approach for the formation of a human tissue biobank. J. Natl. Cancer Inst. Monogr., 2001, (42), 23-24.

[5] Karlsson, J.O.; Toner, M. Long-term storage of tissues by cryopreservation: Critical issues. Biomaterials, 1996, 17(3), 243-256.

[6] Fountain, D.; Ralston, M.; Higgins, N.; Gorlin, J.B.; Uhl, L.; Wheeler, C.; Antin, J.H.; Churchill, W.H.; Benjamin, R.J. Liquid nitrogen freezers: A potential source of microbial contamination of hematopoietic stem cell components. Transfusion, 1997, 37(6), 585-591.

[7] Simione, F.P. Jr. Key issues relating to the genetic stability and preservation of cells and cell banks. J. Parenter. Sci. Technol., 1992, 46(6), 226-232.

[8] European Directive 2010/63/EU. Available to download from http://eur-lex.europa.eu/LexUriServ/LexUriServ.do?uri=OJ:L:2010: 276:0033:0079:en:PDF

[9] EMEA/CHMP/410869. Available to download from http://www.ema.europa.eu/docs/en_GB/document_library/Scientifi c guideline/2009/09/WC500003898.pdf

[10] FDA Draft Guidance for CMC-INDs-21CFR/1270-1271. Available to download from www.mfds.go.kr/jsp/common/downfile.jsp\%3 Ffileinfo\%3D/files/upload/1/TB_F_INFODATA/12018/0aa6f2a7186c4 e9cd6a08770133f0b4b.pdf $+\& \overline{c d}=1 \& h l=e n \& c t=c \operatorname{lnk} \& g l=u k$ 
[11] Brunner, D.; Frank, J.; Appl, H.; Schöffl, H.; Pfaller, W.; Gstraunthaler, G. Serum-free cell culture: the serum-free media interactive online database. ALTEX, 2010, 27(1), 53-62.

[12] Lawson, A.; Ahmad, H.; Sambanis, A. Cytotoxicity effects of cryoprotectants as single-component and cocktail vitrification solutions. Cryobiology, 2011, 62(2), 115-122.

[13] Stoll, C.; Holovati, J.L.; Acker, J.P.; Wolkers, W.F. Synergistic effects of liposomes, trehalose, and hydroxyethyl starch for cryopreservation of human erythrocytes. Biotechnol. Prog., 2012, 28(2), 364-371.

[14] Lynch, A.L.; Chen, R.; Slater, N.K. pH-responsive polymers for trehalose loading and desiccation protection of human red blood cells. Biomaterials, 2011, 32(19), 4443-4449.

[15] Mamprin, M.E.; Petrocelli, S.; Guibert, E.; Rodriguez, J. A novel BES-gluconate-sucrose (BGS) solution for cold storage of isolated hepatocytes. Cryo Letters, 2008, 29(2), 121-133.

[16] Geng, T.; Lu, C. Microfluidic electroporation for cellular analysis and delivery. Lab Chip, 2013, 13(19), 3803-3821.

[17] Shin, M.C.; Zhang, J.; Min, K.A.; Lee, K.; Byun, Y.; David, A.E.; He, H.; Yang, V.C. Cell-penetrating peptides: Achievements and challenges in application for cancer treatment. J. Biomed. Mater. Res. A., 2014, $102(2), 575-587$.

[18] Soejima, K.; Shimoda, K.; Takeuchi, M.; Yamaki, T.; Kono, T.; Sakurai, H.; Nakazawa H. Preliminary report of novel technique for cryopreservation--vacuum-assisted cryoprotectant infiltration. Cryobiology, 2012, 65(1), 21-26.

[19] Crowe, J.H.; Crowe, L.M.; Wolkers, W.F.; Oliver, A.E.; Ma, X.; Auh, J.H.; Tang, M.; Zhu, S.; Norris, J.; Tablin F. Stabilization of dry Mammalian cells: lessons from nature. Integr. Comp. Biol., 2005, 45(5), 810-820.

[20] Huang, Z.; Tunnacliffe, A. Gene induction by desiccation stress in human cell cultures. FEBS Lett., 2005, 579(22), 4973-4977.

[21] Bianchi, G.; Gamba, A.; Murelli, C.; Salamini, F.; Bartels, D. Novel carbohydrate metabolism in the resurrection plant Craterostigma plantagineum. Plant J., 1991, 1355-1359.

[22] Chakraborty, N.; Menze, M.A.; Malsam, J.; Aksan, A.; Hand, S.C.; Toner, M. Cryopreservation of spin-dried mammalian cells. PLoS One, 2011, 6(9), e24916.

[23] Buchanan, S.S.; Pyatt, D.W.; Carpenter, J.F. Preservation of differentiation and clonogenic potential of human hematopoietic stem and progenitor cells during lyophilization and ambient storage. PLoS One, 2010, 5(9), e12518.

[24] Loi, P.; Matsukawa, K.; Ptak, G.; Clinton, M.; Fulka, J. Jr.; Nathan, Y.; Arav, A. Freeze-dried somatic cells direct embryonic development after nuclear transfer. PLoS One, 2008, 3(8), e2978.

[25] Mittal, S.; Devireddy, R.V. Desiccation tolerance of adult stem cells in the presence of trehalose and glycerol. Open Biotechnol. J., 2008, 2, 211-221.

[26] Guo, N.; Puhlev, I.; Brown, D.R.; Mansbridge, J.; Levine, F. Trehalose expression confers desiccation tolerance on human cells. Nat. Biotechnol., 2000, 18(2), 168-171

[27] de Castro, A.G.; Lapinski, J.; Tunnacliffe, A. Anhydrobiotic engineering. Nat. Biotechnol., 2000, 18(5), 473.

[28] Khoo, M.M.; Tyler, P.A.; Saifuddin, A.; Padhani, A.R. Diffusionweighted imaging (DWI) in musculoskeletal MRI: a critical review. Skeletal Radiol., 2011, 40(6), 665-681
[29] Schenz, T.W.; Israel, B.; Rosolen, M.A. Thermal analysis of watercontaining systems. Adv. Exp. Med. Biol., 1991, 302, 199-214.

[30] Chau, D.Y.S.; Collighan, R.J.; Verderio, E.A.; Addy, A.L.; Griffin, $\mathrm{M}$. The cellular response to transglutaminase-cross-linked collagen. Biomaterials, 2005, 26(33), 6518-6529

[31] Chau, D.Y.S.; Collighan, R.J.; Verderio, E.A.; Griffin, M. 2008. Transglutaminase crosslinked collagen biomaterial for medical implant materials. U.S. Patent 0305517, 2008.

[32] Jones, R.A.; Nicholas, B.; Mian, S.; Davies, P.J.; Griffin, M. Reduced expression of tissue transglutaminase in a human endothelial cell line leads to changes in cell spreading, cell adhesion and reduced polymerisation of fibronectin. J. Cell Sci., 1997, 110, 24612472.

[33] Alvey, P.L. An investigation of the centriole cycle using 3T3 and CHO cells. J. Cell Sci., 1985, 78, 147-162.

[34] Huang, Z.; Tunnacliffe, A. Response of human cells to desiccation: comparison with hyperosmotic stress response. J. Physiol., 2004, 558(Pt 1), 181-191

[35] Ho, L.; Muller, R.; Romer, M.; Gordon, K.C.; Heinamaki, J.; Kleinebudde, P.; Pepper, M.; Rades, T.; Shen, Y-C.; Strachan, C.J.; Taday, P.F.; Zeitler, J.A. Analysis of sustained-release tablet film coats using terahertz pulsed imaging. J. Control. Release, 2007, 119, 253-261.

[36] Zeitler, J.A.; Shen, Y.; Baker, C.; Taday, P.F.; Pepper, M.; Rades, T. Analysis of coating structures and interfaces in solid oral dosage forms by three-dimensional terahertz pulsed imaging. J. Pharm. Sci., 2007a, 96, 330-340.

[37] Zeitler, J.A.; Taday, P.F.; Newnham, D.A.; Pepper, M.; Gordon, K.C.; Rades, T. Terahertz pulsed spectroscopy and imaging in the pharmaceutical setting. A review. J. Pharm. Pharmacol. 2007b, 59, 209-223.

[38] Ma, X.; Jamil, K.; Macrae, T.H.; Clegg, J.S.; Russell, J.M.; Villeneuve, T.S.; Euloth, M.; Sun, Y.; Crowe, J.H.; Tablin, F.; Oliver, A.E. A small stress protein acts synergistically with trehalose to confer desiccation tolerance on mammalian cells. Cryobiology, $\mathbf{2 0 0 5}, 51(1), 15-28$

[39] Jin, Y.S.; Kim, G.J.; Jeon, S.G. Terahertz dielectric properties of polymers. J. Korean Physical Soc., 2006, 49(2), 513-517

[40] Berry, E.; Fitzgerald, A.F.; Zinov'ev, N.N.; Walker, G.C.; HomerVanniasinkam, S.; Sudworth, C.D.; Miles, R.E.; Chamberlain, J.M.; Smith, M.A. Optical properties of tissue measured using terahertz pulsed imaging. Proc. SPIE, 2003, 5030, 459-470

[41] Xu, J.; Plaxco, K.W.; Allen, S.J. Absorption spectra of liquid water and aqueous buffers between 0.3 and 3.72 THz. J. Chem. Phys., 2006, 124, 036101

[42] Malik, K.P.; Duru, C.; Ahmed, M.; Matejtschuk P. Analytical options for the measurement of residual moisture content in lyophilized biological materials. Amer. Pharma Rev., 2010, 1-7

[43] CBER (US) guidelines 89D-0140: Centre for Biologics Evaluation and Research, FDA, US. Guideline for the Determination of Residual Moisture in Dried Biological Products. 1990. (www.fda.gov)

[44] Yasui, T.; Araki, T. Sensitive measurement of water content in dry material based on low-frequency terahertz time-domain spectroscopy. Proc. SPIE, 2005, 6024(60240A), 69-74

[45] Hadjiloucas, S.; Karatzas, L.S.; Bowen, W.J. Measurement of leaf water content using terahertz radiation. IEEE Trans. Microwave Theory Tech., 1999, 47, 142-149
Received: March 31, $2015 \quad$ Revised: July 07, $2015 \quad$ Accepted: August 26, 2015 